\author{
Рапакова Т. Б.
}

\begin{abstract}
Аннотация. Цель исследования заключается в создании и презентации модели новой методической системы формирования инфографической компетенции обучающихся военного вуза, приобретаемой в процессе обучения иностранному языку. Статья посвящена вопросу применения инфографики как средства обучения курсантов иностранному языку для формирования инфографической компетенции, сущность и специфика которой детально раскрываются автором. Основное содержание статьи сконцентрировано на модели методической системы, базовых структурных компонентах, их составляющих, обусловленных формируемой компетенцией. Научная новизна представленного исследования заключается в выявлении, систематизации и конструировании единой модели структурных компонентов авторской методической системы, предоставляющей возможность корректно выстраивать процесс обучения иностранному языку с целью формирования инфографической компетенции обучающихся высших военных учебных заведений. Полученные результаты исследования демонстрируют положительный опыт внедрения и апробации новой методики.
\end{abstract}

\title{
Methodology to Develop Military Students' Infographic Competence
}

\author{
Rapakova T. B.
}

\begin{abstract}
The research objective includes development and presentation of the author's original methodology to develop military students' infographic competence in the process of foreign language teaching. The article considers the problem of using infographics while teaching a foreign language to military students with the purpose to develop their infographic competence, the essence and specificity of which are revealed. The researcher's attention is focused on identifying structural components of a methodological system for formation of military students' infographic competence. Scientific originality of the study lies in the fact that the author develops a unified structural model of her original methodological system, which allows achieving optimal organization of foreign language teaching focused on forming military students' infographic competence. The research findings justify efficiency of the proposed methodology.
\end{abstract}

\section{Введение}

Способность современного военного специалиста работать с текстами различного типа воспринимается обществом как обязательная компетенция. Текстовые, графические или составные документы, содержащие одновременно текст и графические элементы: иллюстрации, графики, линии связи (как на языке носителя, так и на иностранных языках), важно уметь воспринимать, интерпретировать, обрабатывать, презентовать по мере необходимости. Обусловлена данная необходимость перегруженностью текстов военного характера различного рода схемами, диаграммами, таблицами, чертежами, что объясняется спецификой военного дела. Тактико-технические характеристики орудия лучше воспринимаются при визуализации их посредством таблицы, чертеж точнее отображает ход снаряда, схема лаконично отражает действия и маневры войск. Тексты такого характера относятся к инфографикам, работа с которыми требует особой подготовки военных специалистов, наличия определенных знаний, навыков и умений, не присвоив которые, специалист не будет способен обеспечить надлежащий уровень реализации поставленной задачи. Следовательно, курсант должен быть подготовлен к выполнению такого рода задач, что, по нашему мнению, может быть обеспечено посредством формирования у обучающихся такой компетенции, как инфографическая, заключающаяся в возможности и способности курсанта интерпретировать и создавать инфографики, в том числе на иностранном языке. Требования к формированию данной компетенции соотносимы со многими из представленных в федеральных государственных образовательных стандартах ВО (№ 672-дсп, № 95, № 930) и квалификационных

Научная статья (original research article) | https://doi.org/10.30853/ped200113

( 2020 Авторы. 000 Издательство «Грамота» (๔ 2020 The Authors. GRAMOTA Publishers). Открытый доступ предоставляется на условиях лицензии СС ВY 4.0 (open access article under the CС BY 4.0 license): https://creativecommons.org/licenses/by/4.0/ 
требованиях к военно-профессиональной подготовке выпускников в качестве дополнения к ФГОС ВО (относительно специальностей и направлений подготовки 11.03.02, 11.05.02 и 56.05.01 от 2017, 2019 гг.). Соотносимы они и с требованиями к способностям осуществления обучающимися критического анализа текста; использования в практической деятельности инструментальных средств компьютерного моделирования (в том числе при применении иностранных языков, в рамках профессионального и академического взаимодействия, решения исследовательских и профилирующих задач); реализации базовых методов и средств извлечения, получения, обработки, анализа и систематизации информации [9-11]. Указанные способности также определяются нами как основополагающие при формировании инфографической компетенции (далее ИК) военного специалиста. Соответственно сопутствующее формирование ИК, с нашей точки зрения, позволит обеспечить должную подготовку курсанта - современного выпускника в рамках присваиваемой квалификации. В свою очередь, формирование ИК реализуемо только при внедрении в процесс обучения особой методической системы, которая представляет собой совокупность ключевых компонентов процесса обучения непосредственно цели обучения, принципов, методов, содержания, организационных форм и средств обучения [13], подсистемами в которой на уровне микроподхода принято выделять преподавателя и обучающихся [15]. Разработка методической системы, планомерное и корректное введение ее в процесс обучения позволят наряду с формированием базовых компетенций у обучающихся осуществлять формирование и ИК. Таким образом, обусловленность требованиями современного общества, системы образования Российской Федерации, нормативно-правовой базы и военной подготовки подтверждает необходимость моделирования методической системы формирования ИК курсантов военного вуза при обучении иностранному языку, что придает особую актуальность исследованию заявленной темы.

Целесообразно в данном контексте отметить, что инфографика представлена многими исследователями новейшим средством и способом обучения (Ж. Е. Ермолаева, Г. П. Климова, В. М. Маслов, М. М. Махрова, С. А. Носков и другие). Однако, акцентируя внимание на обучении непосредственно иностранному языку, представляется важным разработать новую методику, позволяющую дополнить имеющиеся данные изучения вопроса применения инфографики как средства обучения (А. В. Анненкова, Дж. Брэдшоу, А. М. Киселева, Н. Е. Королева, Х. Напарин, И. В. Угликова и другие), и расширить возможности образовательного процесса, осуществляемого в военном вузе, посредством внедрения заявленной методической системы, также как и нового средства обучения иностранному языку - инфографики.

Достижение поставленной цели потребовало решения ряда задач, к числу которых относятся:

- описание сущности формируемой компетенции при обучении иностранному языку;

- установление структурных компонентов методической системы, представление их содержания.

Методы исследования: изучение и анализ нормативных документов, методической, лингводидактической литературы по проблеме исследования; педагогическое моделирование; обобщение педагогического опыта по обучению курсантов иностранному языку; систематизация и классификация; изучение результатов деятельности обучающихся.

Методологическую базу исследования составили положения теории и методики иноязычного профессионального образования (В. Ф. Аитов, Н. И. Алмазова, С. В. Титова, С. В. Чернышев и другие); исследования отечественных и зарубежных учёных об инфографике и ее дидактическом потенциале (Е. Ы. Бидайбеков, Е. З. Власова, Е. И. Казакова, Э. Тафти и другие); совокупность ключевых особенностей применения системного подхода в обучении (В. П. Беспалько, Ф. Ф. Королев, В. Н. Садовский и другие); компетентностного подхода (К. Э. Безукладников, И.А. Зимняя, А. В. Хуторской и другие); интегративного подхода (Дж. Локк, П. И. Образцов, М. С. Пак, К. Д. Ушинский и другие); личностно-деятельностного подхода (Л. С. Выготский, А. Н. Леонтьев, И. А. Зимняя и другие).

Практической значимостью исследования является разработка авторской методической системы формирования инфографической компетенции, успешное внедрение которой в ходе обучения курсантов дисциплине «Иностранный язык» в условиях военного вуза обеспечивает сформированность заявленной компетенции у обучающихся.

\section{Основная часть}

Преимущество введения инфографики на занятиях по иностранному языку как средства обучения заключается в предоставлении неограниченного количества вариаций упражнений и заданий, позволяющих организовать разнообразные формы деятельности обучающихся как под руководством преподавателя, так и при самостоятельно осуществляемой учебной и научно-исследовательской деятельности. Инфографика позволяет прогнозировать содержание темы, вводить и актуализировать знания изученной терминологии, может служить визуальной опорой для восприятия содержания текста на чтение или аудирование, устного высказывания в рамках собеседования на иностранном языке, составления аннотации или тезисов [7, с. 156].

Создание инфографики - это особый вид деятельности курсантов, который, безусловно, требует подготовки, сформированности ИК. Основываясь на прочитанном тексте и опираясь на выявленные ключевые слова, лишь небольшой процент обучающихся может визуализировать его в инфографическом изображении. Практика показала, что к такому числу относятся лишь те курсанты, кто ранее имел опыт создания таковых (в процентном показателе это количество составило $7 \%$ из 100\% опрошенных). Из чего можно прийти 
к выводу, что данную способность курсантов необходимо формировать, а в последующем развивать на более сложном уровне деятельности, нежели учебная, то есть при осуществлении научно-исследовательской деятельности под руководством преподавателя. Определяя сущность сформированной ИК, можно указать, что она заключается в совокупности знаний, умений и навыков, приобретенных обучающимися, которые в последующем обеспечивают способность курсантов интерпретировать, разрабатывать и создавать инфографические изображения, очерчивающие ключевые данные и тему текстового материала, также соответствующие ключевым параметрам, характеристикам и правилам разработки таковых [16]. Курсанты должны знать виды, характеристики и структуру инфографики, требования к ее оформлению, способы, методы и средства разработки, специальную военно-техническую терминологию; уметь воспринимать и интерпретировать данные графически-текстовых изображений на иностранном языке, создавать информационно-графические изображения, осуществлять поиск, критичную оценку и анализ иноязычной информации, находить закономерности, составлять классификации, выявлять ключевую информацию, моделировать инфографику объектов или явлений исследования; обладать навыками осмысленного чтения, критического мышления, структурирования информации и перевода ее в графический вид, систематизации последовательности действий при создании и оформлении инфографики [2]. К ключевым характеристикам инфографики мы относим образность, лаконичность, соотношение текстового и графического материала, структурированность, взаимосвязанность и согласованность всех компонентов, простоту изложения, воспринимаемость, эстетичность, релевантность, функциональность. Курсанты при работе над инфографикой должны руководствоваться сводом правил. Они должны уметь корректно определять тип и формат инфографики, устанавливать логический порядок данных, обеспечивать простоту дизайна, использовать минимум элементов, не перегружать инфографику текстовой информацией, выбирать соответствующий формат чисел, контролировать наличие всех необходимых подписей и названий, применять единую общепринятую цветовую палитру, минимум типов графиков.

В психолого-педагогических исследованиях (А. В. Анненкова, Е. И. Казакова, А. И. Колесникова, И. В. Угликова и другие) отражено положительное влияние наглядности (в нашем случае инфографики) на развитие восприятия, запоминание учебного материала, активизацию умственной деятельности обучающихся, способствующей более глубокому постижению сути изучаемых явлений. Визуализация побуждает к творчеству, помогает развить навык принятия решения, пробуждает интерес к познавательной деятельности, ориентирует на саморазвитие, самоактуализацию $[4 ; 6 ; 7 ; 14]$. ИК, сформированная надлежащим образом, позволяет вывести курсантов на новую ступень интеллектуального развития. Применение современных технологий, средств и знаний курсантами будет актуально не только в период их вузовской подготовки, но и в последующем при выполнении заданий профессионального научно-исследовательского характера.

Опираясь на мысль Л. Н. Попова о полипарадигмальности современного образования [12, с. 15], множественность подходов, к которым мы обращаемся, позволяет нам всецело обозреть основу ИК в разрезе проводимого исследования, так же как и определить первый компонент методической системы как методологический.

Е. В. Аликина справедливо отмечает, что системный подход может обеспечить изучение вопроса, в нашем случае модель методической системы ИК как системного явления, элементы которого расположены в целостном, взаимосвязанном состоянии [1, с. 62]. Единство, целенаправленность и результативность также выступают ведущими характеристиками данного подхода. Соответственно, ориентируясь на поставленную цель, стремимся к результату - сформированной инфографической компетенции курсантов. Ориентируясь на компетентностный подход, мы следуем положениям, выдвинутым И. А. Зимней. Предложенная структура компетентности, составляющими которой автор считает знания, опыт, ценность, эмоционально-волевую регуляцию и готовность [8], в полной мере позволяет управлять и контролировать формирование ИК. Личностно-деятельностный подход задает ориентир на личность обучающегося непосредственно как субъекта деятельности, осуществляющего операции по извлечению и репрезентации, своего рода воспроизведение в новом виде информационного материала при работе с иноязычными инфографиками в заданных условиях. Интегративный подход предусматривает единство цели, принципов, методов, содержания обучения при формировании ИК. Касательно психолого-педагогического аспекта, развитие личности курсанта обеспечивается посредством развития интегрального мышления, в основе которого лежит взаимопроникновение содержания, сознания, деятельности и поведения (О. Е. Галицких), предшествующего опыта, свойств личности, динамики индивидуальных особенностей (А. А. Ельцова).

Определение нормативно-правового компонента дает возможность разрабатывать и регламентировать методическую систему, ссылаясь на нормативно-правовые документы, подчиняя весь процесс обучения текущим требованиям и запросам. Целевой компонент выражается в целеполагании, обеспечивающем последовательность и иерархичность составных элементов методической системы формирования ИК, направленных на достижение предопределенного результата. Содержательный компонент позволяет определить ключевые принципы деятельности при формировании ИК курсантов, также как и лингвистический, экстралингвистический и психологический блоки методической системы. Реализация действий преподавателя и обучающихся в ходе организации и осуществления применения методики может быть обеспечена технологией формирования ИК и обозначена организационно-процессуальным компонентом. В свою очередь, результативно-оценочной компонент ориентирован на презентацию контрольных показателей и уровня результативности применения авторской методики, оценку и анализ достижений. Визуальное восприятие описанной системы обеспечивается представленными краткой (Рисунок 1) и общей моделями методической системы формирования ИК курсантов. 


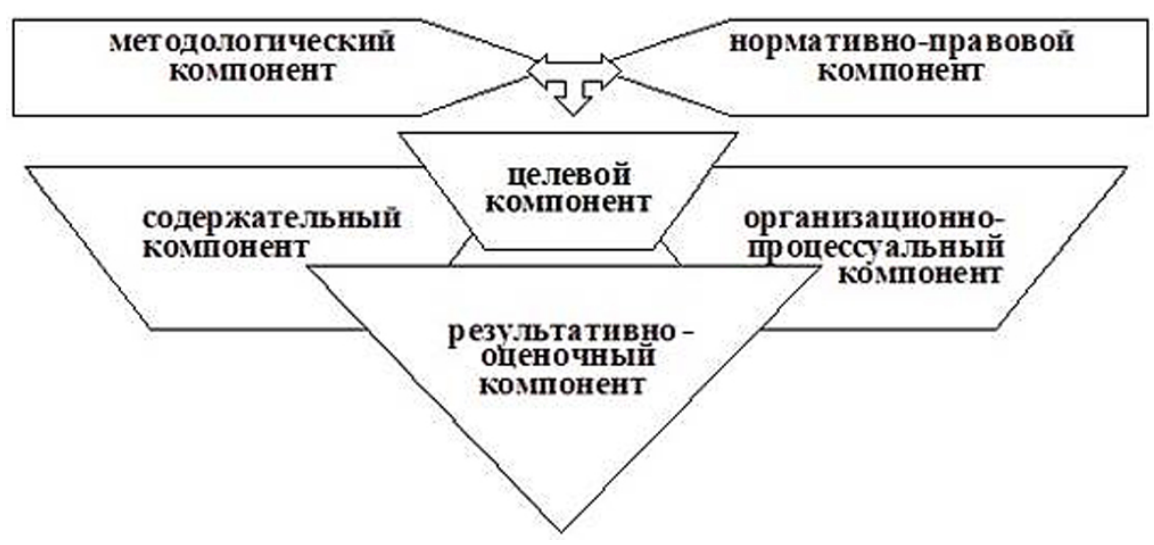

Рисунок 1. Краткая модель методической системы формирования ИК

Общая модель (Рисунок 2) требует ряда пояснений, положительная динамика формирования ИК достигается при условии опоры на ведущие принципы указанных подходов исследования, а именно принципы целостности, иерархичности, структуризации, профессиональной направленности и продуктивности обучения, интегративности, минимакса, деятельности и самодеятельности, самоорганизации, психологического комфорта, учета индивидуальных психологических особенностей и адаптационных процессов обучающихся. Лингвистический блок предполагает единство языкового и речевого профессионально обусловленного материала. Языковой материал определяется иноязычными учебными и научными текстами военной и технической направленности. Речевой материал обозначен ситуативным контекстом (ситуации устного и письменного общения): темами предметного содержания. Экстралингвистический блок освещает особенности инфографем (изображений (рисунков, фотографий, чертежей, знаков); схем (блочных, родовидовых); таблиц (матриц, расписаний); диаграмм (столбиковых, секторных); графиков (линейных, временных); карт (графических, планов)), правила их применения. Психологический блок определяет набор необходимых к присвоению знаний, умений и навыков формируемой компетенции [3].

Составляющими технологии позиционируются этапы организации (информационный, демонстрационный и практический), в ходе которых преподаватель выполняет роль организатора, знакомит курсантов с понятиями «инфографика» и «инфографическая компетенция», наглядно демонстрирует образцы работ, проводит опрос и анкетирование обучающихся, выясняя уровень подготовки и заинтересованности курсантов в подобного рода деятельности, мотивирует на самосовершенствование и саморазвитие; этапы формирования (эмпирический, практико-ориентированный и констатирующий), которые позволяют выстроить учебный процесс посредством применения средств обучения таким образом, чтобы курсанты от деятельности репродуктивного характера (по заданному образцу) смогли перейти к деятельности продуктивного, творческого характера (самостоятельная разработка и создание инфографики), также осуществить самоанализ, самооценку, сделать вывод о достижении поставленной цели, сформированности ИК. Формы (аудиторная, внеаудиторная и самостоятельная работы); методы (словесные, наглядные, практические, репродуктивные, проблемно-поисковые, самостоятельная работа и работа под руководством преподавателя, стимулирования и мотивации интереса к учению) [5]; средства (учебно-методический комплекс); средства контроля (анкеты, опросники, диагностические карты, итоговые контрольные отчеты курсантов) также относятся к составляющим технологии формирования ИК. Результативно-оценочный компонент обеспечивается качественным и количественным показателями. Качество сформированности может быть оценено по уровню сформированности знаний, умений и навыков ИК курсантов, личностного роста, повышению уровня самостоятельности при работе с инфографиками, в свою очередь, количественный показатель результата экспериментальной работы демонстрирует, в полной ли мере реализовалась методическая система, насколько ее применение явилось продуктивным.

Результаты внедрения демонстрационной модели методики формирования ИК курсантов Пермского военного института войск национальной гвардии РФ показали, что она действенна, результативна. Процент курсантов экспериментальной группы, обучившихся интерпретировать иноязычную информацию, отраженную в графическом образе, возрос с 58\% до 78\%. Опыт создания приобрели 93\% курсантов. Знания о требованиях, правилах к разработке уяснили на высоком уровне 63\%, повысили $30 \%$ по сравнению с изначальным количеством, составляющим 15\%. При самооценке $75 \%$ обучающихся определили свой уровень сформированности компетенции как высокий, что не противоречит общей оценке, установленной преподавателеморганизатором. Курсанты на практике демонстрируют знания особенностей, базовых характеристик инфографем, следуют заданным правилам, применяют присвоенные умения и навыки работы с ними, новую терминологию, осуществляют корректный подбор средств наглядности (текстовые, изобразительные, неизобразительные), с легкостью представляют объемный текстовый материал в четкой, лаконичной графической 
форме на иностранном языке, интерпретируют иноязычные инфографики. Рациональность применения ИК при изучении других дисциплин, осуществлении учебной и научной деятельности, дальнейшей профессиональной деятельности также неоспоримо подтверждается практически всеми курсантами.

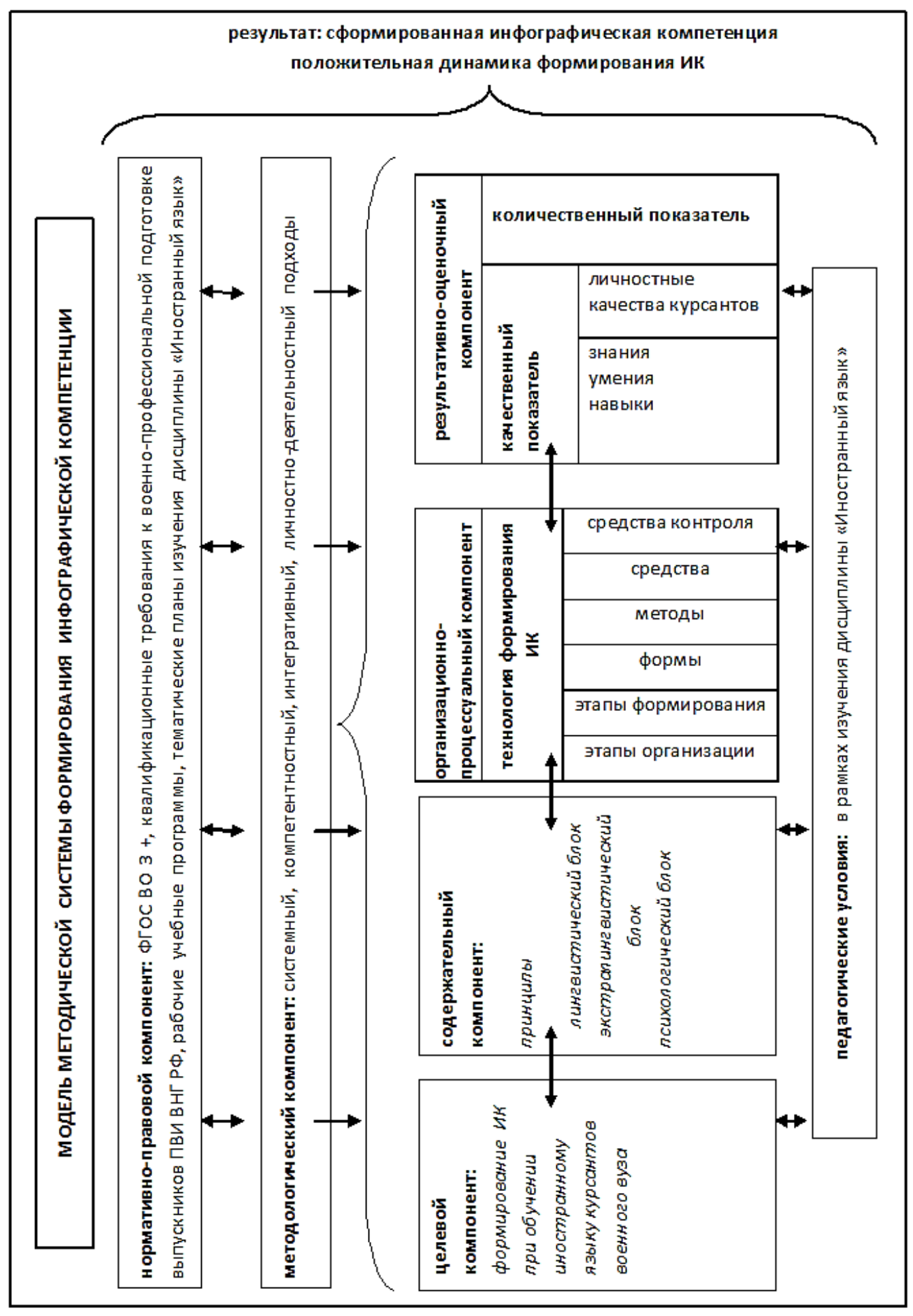

Рисунок 2. Общая модель методической системы формирования ИК

\section{Заключение}

Подводя итог, мы приходим к выводу о том, что предложенная методическая система может быть заявлена как эффективная, комплексная, систематизированная, целенаправленная система, подтверждающая свою продуктивную применимость в условиях военного вуза. Открытость системы позволяет применять ее 
на других площадках, вносить дополнения и коррективы при необходимости. Заявленные нами цель и задачи текущей работы достигнуты: 1) описана сущность ИК при обучении иностранному языку; 2) установлены структурные компоненты методической системы, представлено их содержание.

В дальнейшем мы планируем разработать технологию формирования ИК при обучении курсантов иностранному языку, продолжить опытно-экспериментальную работу по ее апробации, представить комплекс упражнений «Инфографика», позволяющий формировать ИК в учебно-методическом комплексе, для работы с курсантами первого и второго года обучения.

\section{Список источников}

1. Аликина Е. В. Педагогика перевода: монография. Пермь: Изд-во Перм. нац. исслед. политехн. ун-та, 2017. 168 c.

2. Аликина Е. В., Рапакова Т. Б. Формирование инфографической компетенции в научно-исследовательской деятельности курсантов военного вуза в процессе изучения иностранного языка // Вестник Пермского национального исследовательского политехнического университета. Проблемы языкознания и педагогики. 2019. № 1. С. 147-157.

3. Аликина Е. В., Рапакова Т. Б. Формирование инфографической компетенции курсантов как условие текстовой медиации на родном и иностранном языках // Восток - Запад: пересечения культур: II Всемирный конгресс в реальном и виртуальном пространстве: в 2-х т. Киото: Tanaka Print, 2019. Т. 1. С. 198-204.

4. Анненкова А. В. Инфографика как средство формирования современного когнитивного стиля студентов при обучении иностранному языку // Вестник Владимирского государственного университета им. Александра Григорьевича и Николая Григорьевича Столетовых. Серия «Педагогические и психологические науки». 2019. № 36 (55). С. 60-66.

5. Бабанский Ю. К. Избранные педагогические труды / сост. М. Ю. Бабанский. М.: Педагогика, 1989. 560 с.

6. Казакова Е. И. Тексты новой природы: проблемы междисциплинарного исследования // Психологическая наука и образование. 2016. Т. 21. № 4. С. 102-109.

7. Колесникова А. И. Методы визуализации информации при обучении иностранным языкам в неязыковом вузе // Аграрный вестник Верхневолжья. 2017. № 4 (21). С. 152-159.

8. Кондратюк Н. Г. Ирина Алексеевна Зимняя «Компетентностный подход в образовании» [Электронный ресурс] // Текстовые интервью «Беседы с современными классиками» / Психологический институт Российской академии образования. URL: http:/www.pirao.ru/community-projects/text/kompetentnostnyypodkhod-v-obrazovanii/index.php?sphrase_id=10333 (дата обращения: 03.04.2020).

9. Об утверждении Федерального государственного образовательного стандарта высшего образования - бакалавриат по направлению подготовки 11.03.02 Инфокоммуникационные технологии и системы связи [Электронный ресурс]: Приказ Министерства образования и науки РФ от 19 сентября 2017 г. № 930. URL: http://base.garant.ru/71787568/\#ixzz5ku8ezNJu (дата обращения: 12.03.2020).

10. Об утверждении Федерального государственного образовательного стандарта высшего образования по специальности 56.05.01 Тыловое обеспечение (уровень специалитета) [Электронный ресурс]: Приказ Министерства образования и науки РФ от 7 июня 2016 г. № 672-дсп. URL: http://docs.cntd.ru/document/420362636 (дата обращения: 12.03.2020).

11. Об утверждении Федерального государственного образовательного стандарта высшего образования специалитет по специальности 11.05.02 Специальные радиотехнические системы [Электронный ресурс]: Приказ Министерства образования и науки РФ от 9 февраля 2018 г. № 95. URL: http://www.garant.ru/ products/ipo/prime/doc/71791950/ (дата обращения: 12.03.2020).

12. Попов Л. Н. Систематизация методологических принципов (подходов) педагогики // Педагогическое образование в России. 2012. № 1. С. 15-21.

13. Теоретические основы методики обучения иностранным языкам [Электронный ресурс]: учеб.-метод. пособие / Дальневост. федер. ун-т, Школа педагогики; авт.-сост. Т. И. Скрипникова. Владивосток: Дальневост. федер. ун-т, 2017. URL: http://uss.dvfu.ru/e-publications/2017/skripnikova-ti_metodika_obucheniyainostr_yazykam_lektsii_2017.pdf (дата обращения: 15.05.2020).

14. Угликова И. В. Инфографика как способ визуализации информации и знаний студентов неязыковых специальностей в современном иноязычном образовании // Вестник Барановичского государственного университета. Серия «Педагогические науки, психологические науки, филологические науки (литературоведение)». 2019. № 7. С. 84-89.

15. Шукин Н. А. Образование и обучение РКИ: опыт системного подхода // Русский язык за рубежом. 2011. № 1 (224). C. 12-17.

16. Alikina E. V., Falko K. I., Rapakova T. B., Erickson S. Developing Infographic Competence as the Integration Model of Engineering and Linguistic Education // Integrating Engineering Education and Humanities for Global Intercultural Perspectives: Proceedings of the Conference "Integrating Engineering Education and Humanities for Global Intercultural Perspectives”. St. Petersburg, 2020. Vol. 131. P. 692-699. 


\section{Информация об авторах | Author information}

RU Рапакова Татьяна Борисовна ${ }^{1}$

${ }^{1}$ Пермский военный институт войск национальной гвардии Российской Федерации

EN Rapakova Tat'yana Borisovna ${ }^{1}$

${ }^{1}$ Perm Military Institute of National Guard Troops of the Russian Federation

${ }^{1}$ rapakovat@list.ru

\section{Информация о статье | About this article}

Дата поступления рукописи (received): 28.04.2020; опубликовано (published): 31.08.2020.

Ключевые слова (keywords): методическая система; инфографическая компетенция; инфографика; иностранный язык; курсанты военного вуза; methodological system; infographic competence; infographics; foreign language; military students. 